\title{
Implementation of an integrated primary care cardiometabolic risk prevention and management network in Montréal: does greater coordination of care with primary care physicians have an impact on health outcomes?
}

\author{
Sylvie Provost, MD, MSc (1,2,3); Raynald Pineault, MD, PhD (1,2,3,4); Dominique Grimard, MSc (1); \\ José Pérez, MSc (1,2); Michel Fournier, MSc (1); Yves Lévesque, MD, MScA (1); Johanne Desforges, MD (5,6); \\ Pierre Tousignant, MD, MSc (1,2,3,7); Roxane Borgès Da Silva, PhD (3,8)
}

This article has been peer reviewed.

\begin{abstract}
Introduction: Chronic disease management requires substantial services integration. A cardiometabolic risk management program inspired by the Chronic Care Model was implemented in Montréal for patients with diabetes or hypertension. One of this study's objectives was to assess the impact of care coordination between the interdisciplinary teams and physicians on patient participation in the program, lifestyle improvements and disease control.

Methods: We obtained data on health outcomes from a register of clinical data, questionnaires completed by patients upon entry into the program and at the 12-month mark, and we drew information on the program's characteristics from the implementation analysis. We conducted multiple regression analyses, controlling for patient sociodemographic and health characteristics, to measure the association between interdisciplinary team coordination with primary care physicians and various health outcomes.

Results: A total of 1689 patients took part in the study (60.1\% participation rate). Approximately $40 \%$ of patients withdrew from the program during the first year. At the 12-month follow-up ( $\mathrm{n}=992$ ), we observed a significant increase in the proportion of patients achieving the various clinical targets. The perception by the interdisciplinary team of greater care coordination with primary care physicians was associated with increased participation in the program and the achievement of better clinical results
\end{abstract}

Conclusion: Greater coordination of patient services between interdisciplinary teams and primary care physicians translates into benefits for patients.

Keywords: chronic diseases, Chronic Care Model, primary care services, medical practice, coordination of care

\section{Introduction}

Chronic disease management requires integration of the services intended for patients with these types of illnesses. ${ }^{1-3}$ Among the care management models developed to improve case management, the Chronic Care Model (CCM) is the most
Highlights

- The primary care cardiometabolic risk management program implemented in Montréal improves health outcomes among patients with diabetes and hypertension.

- Greater coordination of care between interdisciplinary teams and primary care physicians translates into better outcomes for patients.

- Greater proximity between interdisciplinary teams and primary care physicians, as encouraged in the new primary care organization models, may represent a preferred avenue in the management of chronic diseases.

widely used. It is based on integrating services at various levels of the health care system and is built around six interrelated elements involving different aspects of care organization. ${ }^{3-5}$ One of those elements is the organization of services offer and delivery by setting up coordinated and integrated multidisciplinary teams in which clinical information sharing is systematic. A number of studies show that interventions based on the Chronic Care Model improve care processes and outcomes, particularly with respect to diabetes..$^{5-9}$

Author references:

1. Direction de santé publique du Centre intégré universitaire de santé et services sociaux (CIUSSS) du Centre-Sud-de-l'île-de-Montréal, Montréal, Quebec, Canada

2. Centre de recherche du Centre hospitalier de l'Université de Montréal, Montréal, Quebec, Canada

3. Institut de recherche en santé publique de l'Université de Montréal, Montréal, Quebec, Canada

4. Institut national de santé publique du Québec, Montréal, Quebec, Canada

5. CIUSSS du Centre-Sud-de-l'île-de-Montréal, Montréal, Quebec, Canada

6. Groupe de médecine de famille et Unité de médecine familiale de Verdun, Montréal, Quebec, Canada

7. Department of Epidemiology, Biostatistics and Occupational Health, McGill University, Montréal, Quebec, Canada

8. Faculté des sciences infirmières de l'Université de Montréal, Montréal, Quebec, Canada

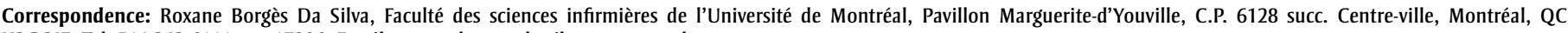
H3C 3J7; Tel: 514-343-6111 ext. 17286; Email: roxane.borges.da.silva@umontreal.ca 
As part of the reform of health care services undertaken in Quebec in recent years, the Health and Social Services Centres (HSSCs) were given a mandate to improve the accessibility, continuity and coordination of services to the population, particularly by fostering interprofessional and interorganizational collaboration within local services networks, including primary care medical services. ${ }^{10,11}$ In this regard, it should be noted that in Quebec, primary medical care services are not fully integrated on an organizational basis with other public health professional services. The implementation of CCM-based initiatives is a method of choice for consolidating network creation. The participation of primary care physicians, who are key players in managing chronic diseases, ${ }^{3,12-15}$ in such integrated services networks produces benefits not only for patients, but also provides invaluable support for their medical practice. ${ }^{16}$

It was in this context that in 2011, Montréal's Health and Social Services Agency (the Health Agency), in conjunction with the HSSCs, ${ }^{*}$ implemented a cardiometabolic risk-management program in primary care for patients with diabetes or hypertension (HT). The program was inspired by the CCM and was aimed at making lifestyle changes, controlling the disease, preventing complications and supporting self-management. In each HSSC, the program provides the following:

- An education centre that offers patients clinical interventions geared toward knowledge, motivation, selfmanagement and lifestyle changes, complementing follow-up by primary care physicians. These interventions are carried out by an interdisciplinary team for patients referred by their family physician. For each patient, the program includes individual follow-up encounters with a nurse and a nutritionist over a period of two years, as well as group meetings with the interdisciplinary team (nurse, nutritionist, kinesiologist, pharmacist and social worker). The sequence of the program's clinical interventions is shown in Table 1. Detailed information on the content of the interventions is available from the authors upon request.

- Support for primary care physicians (e.g. continuing medical education activities, summary of guidelines, written information to be given to patients and program reference tools).
- The establishment and consolidation of links with specialists and among local network partners.

- Mechanisms to coordinate care, notably through implementation of a regional computerized chronic disease registry to facilitate flow of clinical information.

The objectives of the evaluation of the implementation of the program ${ }^{17}$ were to assess the degree to which the program has been implemented in each participating HSSC and to identify the contextrelated factors that could explain the level of implementation; to evaluate the effects of the implementation of the different aspects of the program on patients' health indicators; to assess physicians' participation in the program and their appreciation of the program's effects on their patients and on their practices; and to assess the impact of implementing the program on strengthening local services networks. As part of the evaluation of the implementation of the program, the purpose of this article is to analyze the impact of care coordination between the HSSC interdisciplinary teams and primary care physicians on patient participation in the program

TABLE 1

Clinical interventions sequence in the cardiometabolic risk program, Montréal, Canada

\begin{tabular}{|c|c|c|c|c|c|c|c|c|c|c|c|}
\hline & & Visit 1 & $\begin{array}{c}\text { Visit } 2 \\
1 \text { month }\end{array}$ & $\begin{array}{c}\text { Visit } 3 \\
2 \text { months }\end{array}$ & $\begin{array}{c}\text { Visit } 4 \\
3 \text { months }\end{array}$ & $\begin{array}{l}\text { Visit } 5 \\
4 \text { months }\end{array}$ & $\begin{array}{c}\text { Visit } 6 \\
6 \text { months }\end{array}$ & $\begin{array}{c}\text { Visit } 7 \\
12 \text { months }\end{array}$ & $\begin{array}{c}\text { Visit } 8 \\
15 \text { months }\end{array}$ & $\begin{array}{c}\text { Visit } 9 \\
18 \text { months }\end{array}$ & $\begin{array}{c}\text { Visit } 10 \\
24 \text { months }\end{array}$ \\
\hline \multirow{2}{*}{ 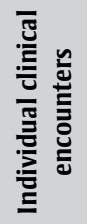 } & Nutritionist & $\mathrm{x}$ & & & $\mathrm{x}$ & & $\mathrm{x}$ & $\mathrm{x}$ & & $\mathrm{x}$ & $\mathrm{x}$ \\
\hline & Nurse & $\mathrm{x}$ & & & & & If HT & $\mathrm{x}$ & & & $\mathrm{x}$ \\
\hline 을 & $\begin{array}{l}\text { Interdisci- } \\
\text { plinary } \\
\text { team }\end{array}$ & & $\mathrm{x}$ & $\mathrm{X}$ & & $\mathrm{x}$ & & & $\mathrm{x}$ & & \\
\hline \multirow{3}{*}{ 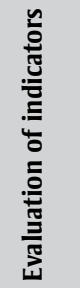 } & Lifestyle & $\mathrm{x}$ & $\mathrm{x}$ & & $\mathrm{x}$ & $\mathrm{x}$ & $\mathrm{x}$ & $\mathrm{x}$ & $\mathrm{x}$ & $\mathrm{x}$ & $\mathrm{X}$ \\
\hline & $\begin{array}{l}\text { Blood } \\
\text { pressure }\end{array}$ & $\mathrm{x}$ & & & & & If HT & $\mathrm{x}$ & & & $\mathrm{x}$ \\
\hline & $\begin{array}{l}\text { Blood tests } \\
\text { (A1c, etc.) }\end{array}$ & $x$ & & & $\mathrm{x}$ & & $\mathrm{x}$ & $\mathrm{x}$ & & $x$ & $\mathrm{x}$ \\
\hline
\end{tabular}

Abbreviation: HT, hypertension.

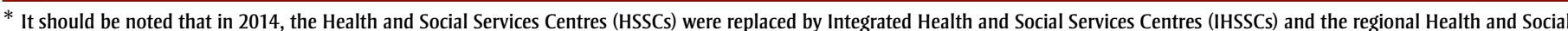

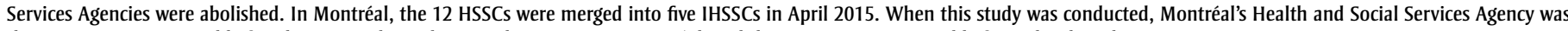
the organization responsible for planning and coordinating the program in Montréal, and the HSSCs were responsible for its local implementation. 
and on lifestyle improvements and disease control.

\section{Methods}

\section{Design}

The evaluation of the implementation of the cardiometabolic risk program was based on a mixed design. We completed the implementation analysis using a qualitative research strategy (conducting semistructured interviews with managers, gathering official documents, administering questionnaires to managers and interdisciplinary team members involved in each HSSC). Detailed results of the implementation analysis will be presented in another article. We used a quantitative approach similar to a quasi-experimental "pre and post" design to analyze the program's impact on patients. We drew the data from self-administered patient questionnaires that were completed onsite at the time of their entry into the program (T0) and at 12 months' follow-up (T12), and from the computerized chronic disease registry in which interdisciplinary team members entered clinical data after each patient encounter. Six of the 12 HSSCs in Montréal took part in the program evaluation. Their selection was based on volunteering and commitment to adhere to the general framework proposed by the Health Agency for the implementation of the program. Data were collected from March 2011 to August 2014.

\section{Definition of variables and data sources}

\section{Dependent variables}

The outcomes studied (dependent variables) regarded program participation and some patient health outcomes. Three variables described the participation of the patients in the program: withdrawals, extent of program exposure and extent of compliance with the program schedule. Withdrawals considered for the analysis were "confirmed withdrawals," i.e. patients who explicitly confirmed to the HSSC team their withdrawal from the program. The extent of program exposure, documented using data from the chronic disease registry, referred to the number of interventions (nutrition, nursing, group meetings) carried out since the patient's entry into the program, regardless of whether the sequence of interventions followed the planned timing. The extent of compliance with the schedule meant, for each patient, the percentage of nutrition, nursing and group interventions that took place within the follow-up time specified in the schedule since the patient's entry into the program. The follow-up times were defined for patients individually on the basis of their date of entry into the program, including an interval to account for the fact that visits did not necessarily take place at the exact time set out in the program schedule.

The patient health outcomes studied included disease control (achievement of glycated hemoglobin [A1c] and blood pressure [BP] targets) and lifestyle (level of physical activity and distribution of carbohydrate intake), as well as the impact of the disease on patient quality of life. We extracted data on disease control and lifestyle variables for each patient taking part in the study from the registry. The A1c values were measured using blood tests performed in a laboratory and entered into the registry by the nurse or the nutritionist. The A1c target achieved variable was dichotomized: less than or equal to $7 \%$ versus more than $7 \%$. BP values were measured using an automatic sphygmomanometer and entered into the registry by the program nurse. The BP target achieved variable was dichotomized: lower than 140/90 (lower than 130/80 for patients with diabetes) versus $140 / 90$ or higher (130/80 or higher for those with diabetes). Data regarding achievement of the physical activity target were documented at each patient visit by means of a brief questionnaire adapted from that used in the Enquête québécoise sur l'activité physique et la santé18 study and entered into the registry by the nutritionist or the kinesiologist. This indicator measured, on a scale of 1 to 4 , the number of days per week on which the patient did at least 30 minutes of physical activity, weighted by physical activity intensity. The physical activity target achieved variable was dichotomized ( 3 or 4 on the fourpoint scale versus less than 3). Measurement of the distribution of carbohydrate intake variable was based on an assessment of the patient's diet performed by the nutritionist at each visit, based on the objectives of daily distribution of carbohydrate intake explained in the Coup d'œil sur l'alimentation de la personne diabétique ${ }^{19}$ document and expressed in two categories: balanced distribution, yes or no.

Questions regarding the measurement of the impact of the disease on patient quality of life were adapted from the Audit of
Diabetes Dependent Quality of Life questionnaire. ${ }^{20-22}$ They measured the patients' perceptions of what the various aspects of their life would look like if they did not have diabetes or hypertension, on a scale ranging from "considerably better" to "the same." The aspects measured included job or career opportunities, social life, sex life, opportunities for sports activities, vacations, travel or leisure activities, motivation to accomplish things, capacity to do physical activity and enjoyment of food. An index of the disease's impact on quality of life was calculated by averaging the responses to the various items, weighted by the importance (from "very important" to "not at all important") the patient gave to each life aspect, reported as a number out of 10 .

\section{Predictor variables}

The two predictor variables in the study, which stemmed from information collected from HSSC program managers and interdisciplinary team members during the implementation analysis, focussed on the program's "external coordination." These variables reflected the coordination of care and interdisciplinary follow-up between the HSSC interdisciplinary teams and the family physicians providing patients' primary care for their diabetes or hypertension. The first variable, documented via questionnaire to HSSC program managers (and confirmed during the semistructured interviews), was the frequency of return of clinical information to physicians. The HSSCs were divided into three categories: high frequency (written communication to the physicians after each individual or group encounter with the patients, and more often if needed), average (communication every six months and more often if needed) and low (once a year or less, or only if needed).

The second variable was HSSC teams' perception of interdisciplinary follow-up and coordination of care with physicians. As part of the implementation analysis, a brief questionnaire was administered to interdisciplinary team members (n varying from 5 to 10) in each HSSC that asked them to rate on a scale of 1 to 5 , where 5 was "very high" and 1 was "very low," the extent of achievement with primary care physicians of the following elements: coordination of care, complementarity of care, interdisciplinary follow-up on patient progress and improvement, interdisciplinary follow-up on laboratory results and 
interdisciplinary follow-up as needed should the patient become unstable. The HSSCs were divided into two categories with regard to the HSSC teams' perception of interdisciplinary follow-up and the coordination of care with physicians: high ( $\geq 60 \%$ of interdisciplinary team members answered 4 or 5 to at least 2 of the 5 questions) and low ( $<60 \%$ answered 4 or 5 to at least 2 of the 5 questions).

\section{Covariates}

Among the control variables used in the analyses, individual characteristics were drawn from the questionnaire administered to the patients at their entry into the program: age, sex, origin, language spoken at home, level of education, occupation, perception of health and number of comorbidities (heart problems, stroke, asthma/ chronic obstructive pulmonary disease, arthritis/osteoarthritis or mental health problems). Primary care clinic type referred to the primary health care organization where the patient receives care for diabetes or hypertension and was identified from patient program registration information. Clinic type could be a family medicine group (FMG); network clinic (NC); combined FMG-NC; local community health centre (LCHC); family medicine teaching unit; non-FMG non-NC group clinic; or solo clinic. The body mass index (BMI) measurement at T0 was drawn from the chronic disease registry. In the analysis models related to patient participation in the program (withdrawal, exposure to the program and compliance with the schedule), the disease's impact on quality of life score at T0 was also included as a covariate, as was the disease knowledge score at $\mathrm{T} 0$. The latter was calculated by averaging the answers to four questions adapted from the work of Battersby et al..$^{23}$ that rated, on a scale of 1 to 4 from "do not agree at all" to "strongly agree", the patient's knowledge of the disease (diabetes or HT), familiarity with the treatment, ability to detect signs and symptoms indicating a change in the progress of the illness and knowledge of what to do should such signs or symptoms occur.

\section{Analysis method}

We constructed multiple regression analysis models, controlling for sociodemographic and health characteristics of patients at $\mathrm{T} 0$, to measure the association between each of the study's dependent variables and 1) frequency of return of clinical information to primary care physicians; and 2) HSSC interdisciplinary team perception of interdisciplinary follow-up and care coordination with primary care physicians. Logistic, linear or Poisson-type regression models were used depending on the nature of the dependent variables.

We analyzed the data using Stata version 13 software (StataCorp LP, College Station, TX, USA). The project received the approval of Montréal's Health and Social Services Agency research ethics committee.

\section{Results}

In total, of the 2810 patients who enrolled in the program from March 2011 to August 2013, 1689 patients took part in the evaluation (participation rate of $60.1 \%$ upon entry into the program). Of those, approximately $40 \%$ withdrew from the program within the first year (n at T12 = 992). Withdrawals occurred mostly (41\%) after the first visit and about $30 \%$ of patients who withdrew said that the program was too long and time consuming. The sociodemographic and health characteristics of patients with at least 12 months of follow-up are presented in Table 2. Among those patients, more than half $(56.9 \%)$ were women, and the average age was 58.5 years. At T0, more than $60 \%$ of the participating patients had an A1c of $7 \%$ or less; more than $40 \%$ had a BP less than 140/90 (130/80 for patients with diabetes), but nearly two-thirds had a BMI of 30 or more and had at least one comorbidity.

At 12 months of follow-up, the patients' average extent of exposure to program interventions was approximately $75 \%$ of the total number of interventions planned by the program, while the schedule compliance rate was approximately $60 \%$. Older patients, patients with a higher level of education and patients without comorbidities had better compliance with the schedule, and they had a lower rate of withdrawal within the first 12 months (data not shown).

The findings presented in Table 3 indicate that at 12 months, there was a significant increase in the proportion of patients who achieved the targets of balanced distribution of carbohydrate intake, A1c of $7 \%$ or less and BP less than 140/90 ( < 130/80 for patients with diabetes). In addition, we noted a significant decrease in the disease's impact on quality of life (the average score went from 4.56 to 4.04 out of 10 ). However, despite a significant increase at three months and six months of follow-up (data not shown), the proportion of patients who achieved the physical activity target had not increased significantly at the 12-month mark.

With respect to patient participation in the program, the results of the multivariate regression analyses indicated that the frequency of communications sent to primary care physicians was associated with greater program exposure and closer compliance with the schedule at the 12-month mark (Table 4). More positive perception by the HSSC program team regarding interdisciplinary follow-up and coordination with primary care physicians was associated with a smaller proportion of program withdrawals and, among patients who withdrew, a smaller proportion of withdrawals before the three-month mark (Table 4). Health outcomes, with the exception of physical activity level, had a positive association with a better perception of the program team with respect to interdisciplinary follow-up and coordination with primary care physicians (Table 5).

\section{Discussion}

Like other studies that suggest that using CCM-based interventions improves glycemic control and blood pressure in patients with diabetes, ${ }^{5-9}$ our findings show that the implementation of the cardiometabolic risk program in Montréal translated into positive health outcomes for patients, particularly in terms of lifestyle modification and achievement of A1c and BP targets.

The cardiometabolic risk program is CCMbased, especially in that it focusses on organizing services offer and delivery around coordinated and integrated multidisciplinary teams, as well as on sharing clinical information. Our findings show that greater coordination of care between the program's interdisciplinary team and primary care physicians, measured by the HSSC program team members' perception of interdisciplinary follow-up and coordination of care with physicians, is associated with better health outcomes for patients. It is interesting to note that this positive association occurs not only with regard to lifestyle modification and A1c and BP control, but also with regard to patients' perception of the impact of their disease on their quality of life. In addition, our results show that greater coordination 
TABLE 2

Characteristics of patients with 12-month follow-up, upon entry into the cardiometabolic risk management program $(n=992)$, Montréal, Canada, 2011-2014

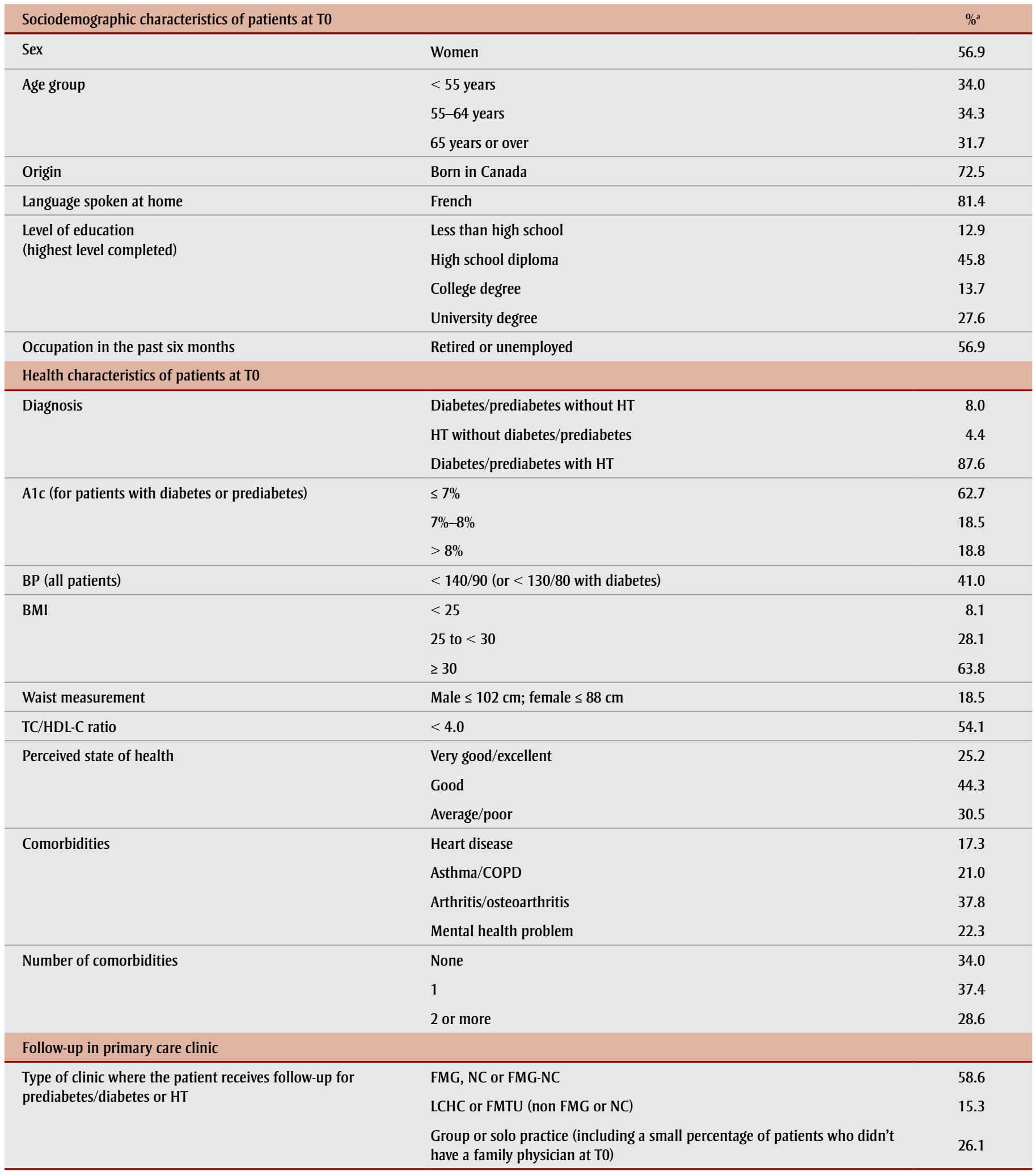

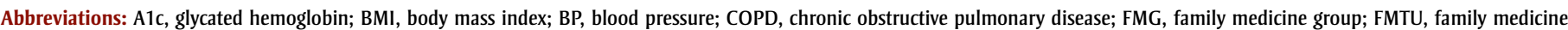

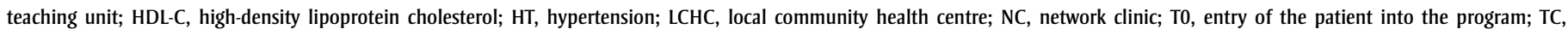
total cholesterol.

a Missing data are excluded from the frequency calculations. 
TABLE 3

Changes in lifestyle, A1c, BP and perceived impact of the disease on quality of life from T0 to T12 in patients with 12-month follow-up, cardiometabolic risk management program, Montréal, 2011-2014

\begin{tabular}{|c|c|c|c|c|}
\hline & \multicolumn{2}{|c|}{$\%$ of patients achieving target values } & \multirow{2}{*}{$\begin{array}{c}\mathrm{N} \text { with measurement at } \\
\text { T0 and T12 }\end{array}$} & \multirow{2}{*}{$p$-value } \\
\hline & at T0 & at T12 & & \\
\hline Level of physical activity $=3$ or 4 on four-point scale & 36.7 & 38.7 & 703 & .312 \\
\hline Balanced distribution of carbohydrate intake & 22.2 & 35.9 & 708 & $<.001$ \\
\hline A1c $\leq 7 \%$ (for those with pre/diabetes) & 66.9 & 72.9 & 602 & $<.001$ \\
\hline \multirow[t]{3}{*}{$\mathrm{BP}<140 / 90$ (with diabetes $<130 / 80$ ) } & 41.8 & 47.1 & 612 & .018 \\
\hline & \multicolumn{2}{|c|}{ Average score /10 } & \multirow{2}{*}{$\begin{array}{c}\mathrm{N} \text { with measurement at } \\
\mathrm{T} 0 \text { and at T12 }\end{array}$} & \multirow{2}{*}{$p$-value ${ }^{\mathrm{a}}$} \\
\hline & at T0 & at T12 & & \\
\hline Impact of the disease on quality of life & 4.56 & 4.04 & 481 & $<.001$ \\
\hline
\end{tabular}

Abbreviations: A1c, glycated hemoglobin; BP, blood pressure; T0, entry of the patient into the program; T12, 12-month follow-up.

${ }^{\text {a }}$ Tests for comparison of $\%$ and of mean scores between T0 and T12 for patients with measurements at both times.

of care with primary care physicians translates into improved program participation by registered patients and lower withdrawal rates (and fewer withdrawals before the three-month mark).

In a systematic literature review looking at the impact of each of the CCM's components on diabetes management in primary care in the United States, Stellefson et al. showed that none of the CCM components was solely responsible for the CCM's outcomes, and that it remained to be determined which combination of the components produced the best outcomes. ${ }^{24}$ It would seem, however, that the implementation of several of the model's components is associated with better patient outcomes..$^{5,24,25}$ Our study does not make it possible to distinguish between the impacts of the program's various components on patient outcomes. However, it suggests that collaborative and coordinated care between interdisciplinary teams and primary care physicians is beneficial to patients. Although our data does not allow us to identify the mechanism responsible for this effect, we can assume that greater coordination of care translates into a better flow of patients' clinical information between the interdisciplinary teams and primary care physicians.

It is interesting to note that favourable perception by HSSC program team members regarding interdisciplinary follow-up and coordination of care with physicians appears to be more systematically associated with better patient outcomes than is

TABLE 4

Association between external coordination with primary care physicians and patient participation in the cardiometabolic risk management program, Montréal, 2011-2014

\begin{tabular}{|c|c|c|c|c|c|c|c|c|c|}
\hline \multirow{4}{*}{ Predictor variables } & & \multicolumn{8}{|c|}{ Outcomes $^{\mathrm{a}}$} \\
\hline & & \multirow{2}{*}{\multicolumn{2}{|c|}{$\begin{array}{l}\text { Confirmed withdrawals } \\
\text { prior to } \mathrm{T}^{\mathrm{b}}{ }^{\mathrm{b}} \\
\mathrm{n}=1015^{\mathrm{c}}\end{array}$}} & \multirow{2}{*}{\multicolumn{2}{|c|}{$\begin{array}{l}\text { Confirmed early } \\
\text { withdrawals (before T3) } \\
\qquad n=388^{c}\end{array}$}} & \multirow{2}{*}{\multicolumn{2}{|c|}{$\begin{array}{l}\text { Program exposure (number } \\
\text { of interventions } / 10 \text { ) at T12 } \\
\qquad n=741^{c}\end{array}$}} & \multirow{2}{*}{\multicolumn{2}{|c|}{$\begin{array}{l}\text { Extent (\%) of compli- } \\
\text { ance with schedule at } \\
\qquad \begin{array}{l}\mathrm{T} 12 \\
\mathrm{n}=741^{\mathrm{c}}\end{array}\end{array}$}} \\
\hline & & & & & & & & & \\
\hline & & $\mathrm{OR}^{\mathrm{e}}$ & $\mathrm{Cl} 95 \%$ & $\mathrm{OR}^{\mathrm{e}}$ & CI 95\% & $\mathrm{IRR}^{\mathrm{e}}$ & Cl $95 \%$ & $\beta^{\mathrm{e}}$ & Cl 95\% \\
\hline \multirow{2}{*}{$\begin{array}{l}\text { Frequency of communications } \\
\text { sent to physicians } \\
\text { (ref: low) }\end{array}$} & Average & 1.33 & 0.86 to 2.05 & 0.86 & 0.43 to 1.71 & $1.20^{*}$ & 1.11 to 1.30 & $9.21^{*}$ & 5.90 to 12.52 \\
\hline & High & 1.28 & 0.84 to 1.95 & 0.85 & 0.43 to 1.67 & $1.07^{* *}$ & 0.99 to 1.15 & 0.95 & -2.17 to 4.06 \\
\hline $\begin{array}{l}\text { Interdisciplinary follow-up } \\
\text { and coordination of care } \\
\text { (ref: lesser) }\end{array}$ & Greater & $0.35^{*}$ & 0.22 to 0.53 & $0.30^{*}$ & 0.12 to 0.77 & 1.01 & 0.95 to 1.08 & -0.69 & -3.36 to 1.99 \\
\hline
\end{tabular}

Abbreviations: $\beta$, linear regression coefficient; $\mathrm{CI}$, confidence interval; IRR, incidence rate ratio; OR, odds ratio; ref, reference category; T, time (in months) from entry into program.

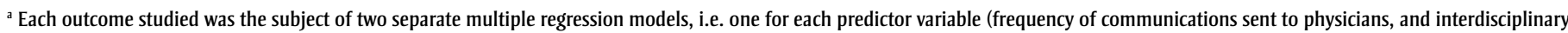
follow-up and coordination of care).

${ }^{\mathrm{b}}$ Confirmed withdrawals prior to T12 $=1(\mathrm{n}=513)$ and patients followed at T12 $=0(\mathrm{n}=992)$.

' $n$ effectively retained in the analyses, excluding missing data.

${ }^{d}$ Confirmed early withdrawals prior to T3 $=1(n=290)$ and confirmed withdrawals at or after T3 = $0(n=378)$.

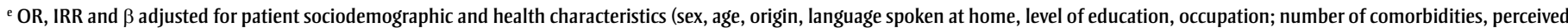

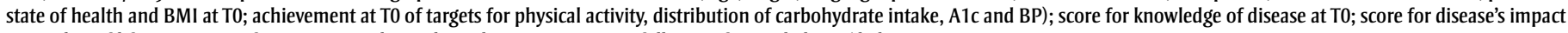
on quality of life at T0; type of primary care clinic where the patient receives follow-up for prediabetes/diabetes or HT.

${ }^{*} p<.05$.

${ }^{* *} p<.10$. 
TABLE 5

Association between external coordination with primary care physicians and achievement of health outcomes at 12-month follow-up in the cardiometabolic risk management program, Montréal, 2011-2014

\begin{tabular}{|c|c|c|c|c|c|c|c|c|c|c|c|}
\hline \multirow{4}{*}{ Predictor variables } & & \multicolumn{10}{|c|}{ Outcomes $^{\mathrm{a}}$ at T12 } \\
\hline & & \multirow{2}{*}{\multicolumn{2}{|c|}{$\begin{array}{l}\text { Level of physical } \\
\text { activity }=3 \text { or } 4 \text { on } \\
\text { four-point scale }{ }^{b} \\
n=650^{c}\end{array}$}} & \multirow{2}{*}{\multicolumn{2}{|c|}{$\begin{array}{l}\text { Balanced distribution } \\
\text { of carbohydrate } \\
\text { intake }^{\mathrm{d}} \\
\mathrm{n}=651^{\mathrm{c}}\end{array}$}} & \multirow{2}{*}{\multicolumn{2}{|c|}{$\begin{array}{l}\mathrm{A} 1 \mathrm{c} \leq 7 \% \mathrm{e} \\
\mathrm{n}=554^{\mathrm{c}}\end{array}$}} & \multirow{2}{*}{\multicolumn{2}{|c|}{$\begin{array}{c}\mathrm{BP}<140 / 90(\text { with } \\
\text { diabetes }<130 / 80)^{\mathrm{f}} \\
\quad \mathrm{n}=564^{\mathrm{c}}\end{array}$}} & \multicolumn{2}{|c|}{$\begin{array}{l}\text { Score }(/ 10) \text { for impact of } \\
\text { disease on quality of life }\end{array}$} \\
\hline & & & & & & & & & & & $n=404^{c}$ \\
\hline & & $\mathrm{OR}^{g}$ & $\mathrm{Cl} 95 \%$ & $\mathrm{OR}^{\mathrm{g}}$ & $\mathrm{Cl} 95 \%$ & $\mathrm{OR}^{\mathrm{g}}$ & $\mathrm{Cl} 95 \%$ & $\mathrm{OR}^{g}$ & $\mathrm{Cl} 95 \%$ & $\beta^{\mathrm{g}}$ & $\mathrm{Cl} 95 \%$ \\
\hline \multirow{2}{*}{$\begin{array}{l}\text { Frequency of communications } \\
\text { sent to physicians (ref: low) }\end{array}$} & Average & 0.81 & 0.48 to 1.35 & $0.23^{*}$ & 0.14 to 0.39 & 0.54 & 0.26 to 1.09 & $1.58^{* *}$ & 0.93 to 2.71 & -0.03 & -0.55 to 0.50 \\
\hline & High & 0.72 & 0.43 to 1.20 & $0.30^{*}$ & 0.18 to 0.49 & 1.24 & 0.59 to 2.63 & $1.92^{*}$ & 1.13 to 3.27 & $-0.64^{*}$ & -1.16 to -0.13 \\
\hline $\begin{array}{l}\text { Interdisciplinary follow-up and } \\
\text { coordination of care (ref: lesser) }\end{array}$ & Greater & 1.07 & 0.70 to 1.63 & $1.51^{*}$ & 1.01 to 2.24 & $2.51^{*}$ & 1.31 to 4.82 & $1.49^{* *}$ & 0.97 to 2.29 & $-0.55^{*}$ & -1.01 to -0.09 \\
\hline
\end{tabular}

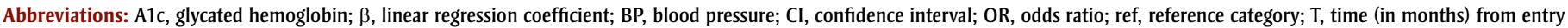
into program.

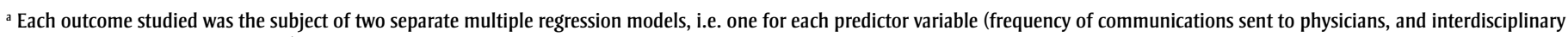
follow-up and coordination of care).

${ }^{\mathrm{b}}$ Level of physical activity of 3 or $4=1(n=272)$ and level of physical activity of less than $3=0(n=431)$.

' $\mathrm{n}$ effectively retained in the analyses, excluding missing data.

${ }^{\mathrm{d}}$ Balanced distribution of carbohydrate intake $=1(\mathrm{n}=254)$ and unbalanced distribution of carbohydrate intake $=0(n=454)$.

${ }^{\mathrm{e}} \mathrm{A} 1 \mathrm{C} \leq 7 \%=1(\mathrm{n}=439)$ and $\mathrm{A} 1 \mathrm{c}>7 \%=0(\mathrm{n}=163)$.

${ }^{\mathrm{f}} \mathrm{BP}<140 / 90$ (with diabetes $\left.<130 / 80\right)=1(n=288)$ and $B P \geq 140 / 90$ (with diabetes $\left.\geq 130 / 80\right)=0(n=324)$.

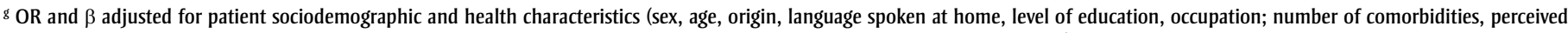

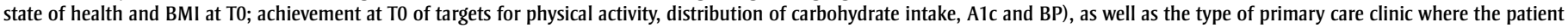
receives follow-up for prediabetes/diabetes or HT.

${ }^{*} p<.05$.

${ }^{* *} p<.10$.

frequency of return of clinical information to physicians. This suggests that the simple implementation of formal communication mechanisms may not be sufficient in itself to foster better health outcomes in this type of program, and that the qualitative aspect of the interaction that develops between interdisciplinary teams and primary care physicians is of sizeable importance. In this regard, our results show no significant association between high frequency of return of clinical information to physicians and achievement of A1c of $7 \%$ or less; they also show a negative association with achievement of balanced distribution of carbohydrate intake. This last result may reflect a policy to increase the frequency of written communications with primary care physicians that may have been adopted by some HSSCs with a higher number of patients having greater difficulty achieving balanced distribution of carbohydrate intake.

Finally, our results show an association between the perceived importance of the interdisciplinary follow-up and the coordination of care with physicians by the program team and a lower patient withdrawal rate. This may be explained by a better coordinated and cohesive transmission of information to patients about the importance of adhering to the program by interdisciplinary team members and primary care physicians in settings where there is a greater coordination of care.

\section{Strengths and limitations}

One of this study's strengths is that it was conducted in a clinical context that reflects the reality of patients and stakeholders, in addition to having been carried out jointly with decision makers and stakeholders. The findings thus reflect the clinical reality, making them easier to generalize to similar contexts. Moreover, linking some organizational characteristics from the implementation analysis to patient outcomes is one of this study's major strengths. The various sources of data available for patient outcomes (questionnaires, clinical data) and the various health outcomes examined also made it possible to document the impact of coordination of care on a number of aspects related to patient follow-up within the program.
In this study, the presence of certain biases cannot be entirely eliminated. Data on lifestyle and perceived impact of the disease on quality of life could therefore include a social-desirability bias. As well, the overall clinical improvement measured in the participating patients may be due, at least in part, to the fact that less motivated patients dropped out of the program. However, it seems unlikely that the potential biases and the withdrawals would have a different impact on the results of the group of patients exposed to the program in the HSSCs where external coordination was greater, and the group exposed to less external coordination.

In addition, variables on lifestyle and A1c and BP control included a certain percentage of missing data at T0 (from $4 \%$ to $8 \%$ ). We applied a hot-deck imputation procedure for missing data, meaning that each missing value was replaced with a randomly selected value from among the values observed in similar patients ${ }^{26}$ with respect to age, sex and whether or not the target for the variable to be replaced was achieved in the next followup time for which these data were available. 
This approach allowed us to reduce the impact of possible nonresponse bias. ${ }^{27}$

With respect to measuring "external coordination," it is important to bear in mind that the organizational characteristics of the program in the HSSCs stem from information collected during the implementation analysis. Their value is therefore the same for all patients registered in the program in a given HSSC. In addition, the relatively low number of participating clinical settings made it more difficult to observe variations and may have led to an underestimation of the strength of the measured associations. Otherwise, the measurement of interdisciplinary follow-up and coordination of care between HSSC program teams and physicians is based on the perception of interdisciplinary team members. The lack of information on the perception of primary care physicians regarding coordination of care with HSSC interdisciplinary teams is a gap.

Lastly, although the program evaluation participation rate was high, our data do not allow us to establish participants' representativeness without a doubt. Available data nonetheless indicate that patients taking part in the evaluation did not differ in any statistically significant manner from all program participants as regards age and sex.

\section{Conclusion}

The implementation of a cardiometabolic risk management and prevention program in Montréal exemplifies the integration of services between interdisciplinary teams and primary care physicians. Even in a context where primary medical care is not fully integrated with other public health professional services, such a program has the potential for successfully integrating services in chronic care management.

Our results show that greater coordination and integration of services to patients between interdisciplinary teams and primary care physicians, as set out in the CCM, translate into beneficial effects for patients with diabetes and hypertension. Particular attention should be paid to coordination and integration of services between interdisciplinary teams and primary care physicians when implementing chronic disease management programs. In that regard, greater proximity between the interdisciplinary teams and primary care physicians, as encouraged in the new primary care organizational models that include such teams, may represent a preferred avenue in the management of chronic diseases.

\section{Acknowledgements}

The evaluation of the implementation of the cardiometabolic risk program in Montréal was funded by the Canadian Institutes of Health Research (Partnerships for Health System Improvement program) and the Pfizer-FRSQ (Fonds de recherche en santé du Québec)-MSSS (Ministère de la Santé et des Services sociaux) Chronic Disease Fund. The authors would like to recognize the contribution of project collaborators at Montréal's Health and Social Services Agency and participating Health and Social Services Centres (Sud-OuestVerdun, Jeanne-Mance, Cœur-de-l'île, Pointe-de-l'Île, St-Léonard-St-Michel and Bordeaux-Cartierville-St-Laurent).

\section{Conflicts of interest}

The authors declare that there is no conflict of interest regarding the publication of this paper.

\section{Authors' contributions}

Sylvie Provost, Raynald Pineault, Dominique Grimard, Pierre Tousignant, Johanne Desforges and Roxane Borgès Da Silva contributed to the concept and design of the study; data gathering, analysis and interpretation; and preparing the manuscript for submission. José Pérez, Michel Fournier and Yves Lévesque contributed to the data analysis. All the authors have been involved in drafting the manuscript; they also read and approved the final manuscript.

\section{References}

1. Wagner, EH. The role of patient care teams in chronic disease management. BMJ. 2000;320(7234):569-72.

2. Von Korff M, Glasgow RE, Sharpe M. Organising care for chronic illness. BMJ. 2002;325(7355):92-4.

3. Rothman AA, Wagner EH. Chronic illness management: what is the role of primary care? Ann Intern Med. 2003;138(3):256-61.

4. Wagner EH, Austin BT, Davis C, Hindmarsh M, Schaefer J, Bonomi A. Improving chronic illness care: translating evidence into action. Health Aff. 2001;20(6):64-78.
5. Nutting PA, Dickinson WP, Dickinson LM, et al. Use of Chronic Care Model elements is associated with higherquality care for diabetes. Ann Fam Med. 2007;5(1):14-20.

6. Bodenheimer T, Wagner EH, Grumbach $\mathrm{K}$. Improving primary care for patients with chronic illness: the Chronic Care Model, Part 2. JAMA. 2002;288(15): 1909-14.

7. Coleman K, Austin BT, Brach C, Wagner EH. Evidence on the Chronic Care Model in the new millennium. Health Aff. 2009;28(1):75-85. doi: 10.1377/hlthaff.28.1.75.

8. Glasgow RE, Orleans CT, Wagner EH, Curry SJ, Solberg LI. Does the Chronic Care Model serve also as a template for improving prevention? Milbank Q. 2001;79(4):579-612.

9. Tsai AC, Morton SC, Mangione CM, Keeler EB. A meta-analysis of interventions to improve care for chronic illnesses. Am J Manag Care. 2005; $11(8): 478-88$

10. Breton M, Denis JL, Lamothe L. Incorporating public health more closely into local governance of healthcare delivery: lessons from the Québec experience. Can J Public Health. 2010;101(4):314-17.

11. Breton M, Pineault R, Levesque JF, Roberge D, Borgès Da Silva R, Prud'homme A. Reforming healthcare systems on a locally integrated basis: is there a potential for increasing collaborations in primary healthcare? BMC Health Serv Res. 2013;13(262). doi: 10.1186/1472-6963 $-13-262$.

12. Bodenheimer $\mathrm{T}$, Wagner $\mathrm{EH}$, Grumbach K. Improving primary care for patients with chronic illness. JAMA. 2002; 288(14):1175-9.

13. Grumbach K. Chronic illness, comorbidities, and the need for medical generalism. Ann Fam Med. 2003;1(1): 4-7. doi: 10.1370/afm.47.

14. Starfield B, Lemke KW, Bernhardt T, Foldes SS, Forrest CB, Weiner JP. Comorbidity: implications for the importance of primary care in "case" management. Ann Fam Med. 2003; 1(1):8-14. doi: 10.1370/afm.1. 
15. Reeve J, Blakeman T, Freeman GK, et al. Generalist solutions to complex problems: generating practice-based evidence-the example of managing multi-morbidity. BMC Fam Pract. 2013;14(112). doi: 10.1186/1471-2296 $-14-112$.

16. Provost $S$, Borgès Da Silva $R$, Pineault R, Grimard D, Pérez J, Tousignant P. Mise en œuvre d'un programme de prévention et d'intervention interdisciplinaire intégré sur le risque cardiométabolique en première ligne : le point de vue des médecins participants. Poster presentation. Abstract $\# 70$. CAHSPR Conference, 2016 May; Toronto, Canada.

17. Provost S, Pineault $\mathrm{R}$, Tousignant $\mathrm{P}$, Hamel M, Borgès Da Silva R. Evaluation of the implementation of an integrated primary care network for prevention and management of cardiometabolic risk in Montréal. BMC Fam Pract. 2011;12(126). doi: 10.1186/1471-2296 $-12-126$.

18. Nolin B, Prud'homme D, Godin G, Hamel D. Enquête québécoise sur l'activité physique et la santé 1998. SainteFoy (QC): Institut de la statistique du Québec, Institut national de santé publique du Québec et Kino-Québec; 2002.

19. Ministère de la Santé et des Services sociaux. Coup d'œil sur l'alimentation de la personne diabétique [Internet]. Québec (QC): Ministère de la Santé et des Services sociaux; 2014. Available from: http://www.diabete.qc.ca/en /understand-diabetes/resources /getdocumentutile/coup-oeil-diabeteEN .pdf

20. Bradley C, Todd C, Gorton T, Symonds E, Martin A, Plowright R. The development of an individualized questionnaire measure of perceived impact of diabetes on quality of life: the ADDQoL. Qual Life Res. 1999;8(1-2):79-91.

21. El Achhab Y, Nejjari C, Chikri M, Lyoussi B. Disease-specific healthrelated quality of life instruments among adults diabetic: a systematic review. Diabetes Res Clin Pract. 2008;80(2):171-84. doi: 10.1016/j. diabres.2007.12.020.
22. Speight J, Reaney MD, Barnard KD. Not all roads lead to Rome: a review of quality of life measurement in adults with diabetes. Diabet Med. 2009;26(4): 315-27. doi: 10.1111/j.1464-5491.2009 $.02682 . x$.

23. Battersby MW, Ask A, Reece MM, Markwick MJ, Collins JP. The Partners in Health scale: the development and psychometric properties of a generic assessment scale for chronic condition self-management. Aust J Prim Health. 2003;9(4):41-52. doi: 10.1071/PY03022.

24. Stellefson M, Dipnarine K, Stopka C. The Chronic Care Model and diabetes management in US primary care settings: a systematic review. Prev Chronic Dis. 2013;10:120180. doi: 10.5888/ pcd10.120180.

25. Elissen AM, Steuten LM, Lemmens LC, Drewes HW, Lemmens KM, Meeuwissen JA, et al. Meta-analysis of the effectiveness of chronic care management for diabetes: investigating heterogeneity in outcomes. J Eval Clin Pract. 2013;19(5):753-62. doi: 10.1111/j.1365-2753.2012.01817.x.

26. Andridge RR, Little RJ. A review of hot deck imputation for survey nonresponse. Int Stat Rev. 2010;78(1): 40-64. doi: 10.1111/j.1751-5823.2010 .00103.x.

27. Haziza D. Chapter 10: Imputation and inference in the presence of missing data. In: Pfeffermann D, Rao CR (eds). Handbook of Statistics 29A: Sample surveys: design, methods and applications. Oxford (UK): Elsevier; 2009: 215-46. 